\title{
Consequences of gynecological cancer in patients and their partners from the sexual and psychological perspective
}

\author{
Dariusz lżycki ${ }^{1}$, Katarzyna Woźniak², Natalia lżycka \\ ${ }^{1}$ Department of Cancer Immunology, Faculty of Medicine II, Poznan University of Medical Sciences, Poznan, Poland \\ ${ }^{2}$ Postgraduate studies, Faculty of Medicine II, Poznan University of Medical Sciences, Poznan, Poland \\ ${ }^{3}$ Poznan University of Medical Sciences, Poznan, Poland
}

\begin{abstract}
The diagnosis of gynecological cancer and the following consequences of the treatment radically change the lives of cancer patients and their partners. Women experience negative consequences in terms of sexual, psychological and social functioning. Surgical treatment may result in a decrease in sexual pleasure and pain during intercourse. Chemotherapy and radiotherapy can cause a loss of libido and negatively affect the capacity to experience pleasure or orgasm.

Treatment-related changes may include the occurrence of body image disorders, decreased quality of life as well as depressive and anxiety disorders among patients. Furthermore, a negative influence on the relationship between the affected women and their partners, as well as an adverse effect on the social activity, can be observed. Cancer is not an individual experience. It also affects partners of the sick women in terms of psychological and sexual functioning.

This article depicts possible problems encountered by cancer patients and their partners from the psychological and sexual perspective. The emphasis is put on understanding sexuality not only in the context of sexual performance, but also in a wider perspective.
\end{abstract}

Key words: oncology, psychology, gynecological cancer, sexuality, male partners.

\section{Introduction}

Treatment of gynecological cancer may be associated with negative consequences related to sexual, psychological, and social functioning both in women and their partners [1]. According to the World Health Organization (WHO), sexuality, together with sex, sexual identity, orientation, eroticism, pleasure, intimacy and reproduction, is one of the central aspects of human lives. Sexuality comprises thoughts, fantasies, attitudes, roles, behaviors, and desires. It depends on biological, psychological, social, cultural, historical and legal factors [2]. The sexuality of women is a complex process, including many different aspects [3], and can be analyzed in three different spheres: physical, psychological, and social [4]. The physical component refers to the capacity of experiencing sexual excitement and obtaining physical satisfaction. The psychological component applies to affective and cognitive processes preceding and appearing during sexual reactions. The social component pertains to the relation with the partner and the need to enter into an intimate relation. Cancer treatment and its consequences may induce physiological barriers and the following psychological difficulties, which may hinder sexual reactivation. In the psychological domain, some women may experience body image disorders, negative auto-judgmental thoughts, depression, and anxiety - all of which may aggravate sexual and social functioning. Also, partners of the affected women face problems with sexuality, intimacy, and psychological strain, resulting from the sense of distress, burden, and changes within the relationship.

\section{Sexual and psychological functioning among women with gynecological cancer}

\section{Consequences of the treatment}

The treatment of gynecological cancer is very often associated with the occurrence of poor sexual functioning [5], or even sexual dysfunctions (SD) [6]. Those difficulties can be caused by changes in the hormonal secretion levels or removal of the reproductive organs. Hysterectomy may be associated with loss of sexual pleasure as the uterus plays an integral role in sexual reactions. Ovariectomy decreases estrogen secretion and, in consequence, diminishes the level of lubrication in the vagina [7]. Vulvectomy changes the appearance and 
functioning of the genitals. Pelvic surgery can damage the nerves. Chemotherapy causes the decrease in the libido, fatigue, and temporary or permanent menopause. It can also cause neuropathy of the clitoris, which affects the desire and sexual pleasure. Radiotherapy may damage the vaginal tissues, nerves or blood vessels [3]. It can also cause the following sexual problems: vaginal atrophy, vaginal stenosis, and loss of tissue flexibility [8].

Painful intercourse remains the most common sexual problem reported by cancer patients [9]. According to some authors, almost $70 \%$ of gynecological patients are at risk of dyspareunia associated with impaired vaginal elasticity [10]. Other problems include vaginal lubrication dysfunction, bleeding after coitus, decreased sexual activity due to fatigue, limited capability to achieve sexual arousal and orgasm, diminished sensitivity of sexual organs $[11,12]$, sense of numbness [13], fear that the intercourse would cause health injury or that the cancer might be sexually transmitted [14].

\section{Psychological consequences}

The treatment and its effect on sexual functioning cause psychological aftermaths in gynecological cancer patients. These consequences depend on the cancer type, timing of the diagnosis, and the applied treatment [15]. According to some authors, patient quality of life (QoL) remains unchanged in spite of the onerous therapy [16-18]. For example, in a study conducted by Jaruskowa [19], no differences were observed in sexual functioning of patients undergoing treatment for cervical and endometrial cancer in comparison to mild gynecological lesions and cancer patients before surgery. A study by Rowlands et al. [20] demonstrated that onethird of uterine cancer patients reported high sexual comfort within 3 to 5 years after surgery. It has to be noted that the highest scores were obtained by older women, who were less educated, had lower levels of depression at the time of diagnosis, and underwent only surgical treatment. However, another study revealed that even up to $80 \%$ of women diagnosed with gynecological cancer experience sexual dysfunctions [21].

Interest in sexual activity is connected with the treatment stage and well-being of the patient. At diagnosis, many women experience a complete loss of sexual drive. During the treatment, sexual activity remains low or rises, depending on the psycho-physical condition of the patient and the belief about the influence of sex on health. Notably, sexual life after treatment completion becomes a challenging issue for many women. Diminished sexual desire may lead to sexual abstinence and, in extreme cases, to sexual aversion [14], and in some women it may also cause distress. Lack of information about the treatment and its consequences leads to lack of understanding of the situation and intensifies the sense of tension among the patients
[7]. Women who experience discomfort during the intercourse have a tendency to avoid sexual contacts if they cannot openly communicate the problem to their partners. A good relationship with the partner constitutes a succoring/supporting factor in the coping process [18]. Satisfaction from sexual life is not limited to the quality of sexual functioning defined as the number of intercourses with the partner. Satisfactory experiences are associated with the possibility of feeling intimate rather than having sex only.

A combination of different types of treatment promotes the occurrence of negative symptoms and reinforces adverse psychological consequences. There is strong evidence that cancer treatment is associated with negative consequences in many areas of patient life [14]. In case of gynecological patients, sexual dysfunctions, resulting from the treatment routine, may have a disruptive influence on their personal relations or the sense of sexual identity. In this sense, dysfunctions affect coping and QoL [22]. The most commonly reported problems include decreased interest in sexual life, and a negative shift in perceiving the body image and themselves as sexual beings [23]. Other issues mentioned in the literature are decreased QoL, satisfaction with the relationship, depression, and anxiety [8]. Women in the reproductive period who become infertile due to the treatment may perceive themselves as incomplete, insufficient, or worthless [14]. Those attitudes may be favored by the conviction that femininity corresponds to the ability to bear children [24]. Premature menopause may have a vastly negative impact on the interest in sexual activity and sexual functioning, causing vaginal dryness, hot flashes, insomnia, and emotional dysregulation [3]. Another reported problem is pain, which decreases sexual pleasure and impedes orgasm [7]. Sexual dysfunctions may be accompanied by anxiety relating to sexual activity $[1,14]$. For example, in a study by Lindau et al. [25], one of the concerns reported by the patients was the level of their sexual performance in terms of feeling pleasure and having orgasms. Painful intercourse was interpreted as a signal of disease recurrence by some of them. Fear of pain may also influence a decision to avoid sexual contacts [26].

Treatment of gynecological cancer very often implies changes in the body appearance. Scarification or loss of organs commonly associated with the concept of femininity may provoke a distorted body image and the following sense of sadness and sufferance [14]. Body image has been defined as the picture of the body which is formed in the mind of an individual. Among other things, the term includes the sense of being feminine and attractive. Gynecological cancer patients report lower self-esteem and attractiveness, as well as feeling insecure about their sexuality [27]. Loss of organs like the uterus or the ovaries for many women has a symbolic meaning, depriving them of their femininity [28]. 
A study of Green et al. [29] showed that 41 patients who underwent the surgery reported changes in the body image and perceived themselves as inadequate, not meeting the common standards of beauty. In reference to their bodies, women may use negative descriptions, e.g. asymmetrical, incomplete, destroyed. In fact, body image and sexuality are often considered in terms of time perspective: before and after the surgery. The diagnosis and the subsequent treatment are the defining moments for the sexual functioning [30]. Self-schemas seem to play an important role in the process of coping [28]. Self-schemas are defined as a permanent and stable set of convictions, attitudes, experiences and generalizations about oneself. They also refer to sexuality, incorporate past experiences, and are expressed in the form of decisions, judgments, prejudice, and behaviors. Gynecological cancer patients with a negative sexual self-schema report a higher sexual dysfunction. It is assumed that those women are less open to different sexual experiences and have generally a negative attitude towards sex. As a result, they might be less interested in sexual activity or experimenting, and more ashamed with the changes of their bodies [13].

The consequences of cancer and its treatment may be associated with a diminished level of QoL [31, 32]. Reis et al. [14] conducted a study on 100 women assessing the level of their sexual functioning and its relation to QoL after treatment. Most women reported low to moderate levels of QoL. Low scores correlated with higher levels of anxiety and depression. According to Frumovitz et al. [33], also the type of the treatment influences the levels of well-being in gynecological cancer patients. Women with cervical cancer after hysterectomy had a higher level of QoL in comparison to those who underwent radiotherapy as well. The timing of the diagnosis also seems to be associated with the QoL level [12].

Similarly to other types of cancer [34], women with gynecological cancers suffer from depression and distress [35, 36], PTSD symptoms, anxiety [37], or even suicidal ideation [38]. Depressive and distress symptoms may be associated with the levels of sexual dysfunction [22]. Depression is one of the main reasons for a decreased libido. Problems in sexual life may also cause negative feelings like frustration, anger, sadness, and shame, further deteriorating a generally poor psychological condition [30].

\section{Social consequences}

Social consequences of cancer may manifest themselves in the area of the relationship with the partner and family, group functioning, and role taking. Some patients find it difficult to pick up the old roles which can slow down the process of social rehabilitation [39]. The symptoms, e.g. constant fatigue, edema, lack of comfort while sitting, losing control of urine, or nausea may also limit outdoor activity [40].

Changes caused by the treatment may bring about the fear of losing the partner or, in case of single women, not finding one [3]. Diminishing satisfaction with the relationship can be accompanied by lower QoL as well as higher levels of anxiety and depression in cancer patients and their partners [41]. Sexual dysfunction issues seem to be the most troubling for the patients, who may consider decreased sexual performance as a threat to their relationship [7]. The consequences of the treatment related to the alteration of body appearance are believed to be the reason for the absence of sexual interest in the partner [1]. Numerous cancer patients decide to distance themselves physically and emotionally from their partners in order to avoid being rejected [3]. Lack of communication concerning sexual issues may even deepen those feelings [28]. In a study of Juraskowa et al. [24], women described the difficulties of their partners to accept the diagnosis and the following lack of communication. Absence of speaking hinders the process of setting new rules of sexual functioning. For many women a satisfactory sexual relation does not necessarily include intercourse [28], but they fear that this type of arrangement would be unacceptable for their partners. Therefore, the interest of their partner in sexual activity can be considered by some of them as burdening and threatening [23]. Changes in sexual functioning of a couple demand a renegotiation of the old sexual life rules, which is not always easy for the partner, who may find it difficult to alter his role from a caregiver to a lover. Partners who provide intimate care to their sick spouses may find it challenging to perceive them as sexually attractive [42]. Furthermore, some of them may believe that their needs are secondary [43]. Problems in a relationship and sexual life may be associated with the lack of basic knowledge about cancer, treatment, and its consequences both in patients and their partners. It is considered a good practice to engage the partner as well during medical consultations [44].

\section{Consequences of gynecological cancer for the partners of the affected women}

Cancer is not an individual experience as it concerns the entire family [45]. Caring for a sick person is often accompanied by the feelings of burden and fatigue. Partners of cancer patients may experience comparable or even higher levels of distress in comparison to their sick spouses. Distress may be followed by elevated levels of depression and anxiety, together with low QoL. Feelings of loneliness, hopelessness, insecurity, life crisis [46], and resigning from their own needs [47] may occur. Mental problems may coincide with physical health issues $[48,49]$. Partners are at risk of developing health complications in the absence of support and relation- 
ship problems. Rohleder et al. [50] reported that a year after the initial diagnosis, the partners were diagnosed with malfunction of the neurohormonal and immunological systems. Their study confirms the results of yet another study [51], which reported that the morbidity rates in elder caregivers increased $>63 \%$ within 4 years since the diagnosis.

Studies concerning the psychosomatic condition of gynecological cancer patients are published randomly [52], and only a few have shown that QoL and sexual issues following cancer affect both the patients and their partners [43]. Unsatisfying relationship and sexual needs have been increasingly reported. Butow et al. [53] state that the most commonly unfulfilled needs of partners of ovarian cancer patients at the end of life were coping with emotions, fear of disease development, balancing between needs of the patient and their own needs, the influence of caregiving on their professional life, and feeling insecure about the future. Men can also experience contradictory feelings, e.g. concern about the health of the partner, a need for the initiation of sexual contacts and the accompanying sense of guilt, which can drive the partners apart and provoke conflicts [54].

Sexual concerns of the partners of gynecological cancer patients include decreased libido, feelings of being unwanted and unattractive, and fear of restarting sexual activity. Partners may also report feelings of sexual distress such as guilt, grief, or feeling lonely in the sexual relationship. Interestingly, much less sexual distress may be observed in couples which started their relation more recently rather than those in long-term relationships [55]. The study of Lalos et al. [56] reported that partners of cervical and endometrial cancer patients experienced a psychological crisis at the beginning of the treatment. After a year, the psychosomatic symptoms kept increasing, followed by interpersonal problems between the male partners and their relatives and friends. Also, the sexual life of the couple worsened. The men started experiencing sexual dysfunction concerning the sexual desire. Additionally, Andersen et al. [57] reported problems with erection. It is assumed that the loss of sexual satisfaction and libido is partially influenced by the sickness of the partner [58]. The fact that cancer has a negative effect on sexuality has been confirmed by Hawkins et al. [42], who reported that even up to $71 \%$ of the partners experience unfavorable changes in their sexual lives after the diagnosis. Abstinence from sexual activity is also associated with the decreased intimacy in the couple. Psychosexual healthcare needs concern both the patients and their partners, and all of them should have an easy access to sexual healthcare specialists [59-61], especially as different models of sexual healthcare for cancer patients are being constantly developed and prove to be efficient in helping the patients [62-64].

\section{Conclusions}

Gynecological cancer patients are at risk of developing sexual and psychological problems. It is believed that social support is a buffer against the occurrence of mental issues. Social support moderates the relation between cancer symptoms, treatment, and adaptation to the new situation. It can protect against depression or cancer-specific distress. Partners of cancer patients do not always have the skills to provide adequate support to their female partners. Numerous authors have demonstrated that the partners also require family or professional help. Unfortunately, communication between the couples and healthcare professionals is very unsatisfactory, possibly due to lack of knowledge and practice in providing information and support concerning sexual, relational, and emotional issues. Effective communication models between healthcare professionals, patients and their partners have been successfully developed. Unfortunately, there are few courses providing practical knowledge to medical students, doctors, nurses or other healthcare professionals in Poland. In light of the existence of a relationship between sexual dysfunctions and their psychological and social consequences in gynecological cancer patients and their partners, more attention should be paid to psychoeducation of the patients and their partners in daily clinical practice. The matter of educating healthcare professionals should be also taken under consideration.

\section{Disclosure}

Authors report no conflict of interest.

\section{References}

1. Abbott-Anderson K, Kwekkeboom KL A systematic review of sexual concerns reported by gynecological cancer survivors. Gynecol Oncol 2012; 124: 477-489.

2. World Health Organization (SUI). Definition of sexuality and sexual health [Internet]. http://www.who.int/reproductivehealth/topics/sexual_health/ sh_definitions/en/ Pobrano: 07.12.1014.

3. Hughes MK. Alternations of sexual function in women with cancer. Semin Oncol Nurs 2008; 24: 91-101.

4. Basson R. Biopsychosocial models of women's sexual response: Appreciation to management of desire disorders. Sex Relation Ther 2003; 18 : 107-115.

5. Li CC, Rew L, Chen L Factors affecting sexual function: A comparison between women with gynecological or rectal cancer and healthy controls. Nurs Health Sci 2014; 23. DOI: 10.1111/nhs.12177.

6. Jensen PT. Gynecological cancer and sexual functioning: Does treatment modality have an impact? Sexologies 2007; 16: 279-285.

7. Stead ML, Fallowfield L, Selby P, Brown JM. Psychosexual function and impact of gynecological cancer. Best Pract Res Clin Obstet Gynaecol 2007; 21: 309-320.

8. Aerts L, Enzlin P, Vergote I, et al. Sexual, psychological, and relational functioning in women after surgical treatment for vulvar malignancy: a literature review. J Sex Med 2012; 9: 361-371.

9. Jensen P, Groenvold M, Klee M, et al. Early-stage cervical carcinoma, radical hysterectomy, and sexual function. Cancer 2004; 100: 97-106.

10. Stinesen Kollberg K, Waldenström AC, Bergmark K, et al. Reduced vaginal elasticity, reduced lubrication, and deep and superficial dyspareunia in irradiated gynecological cancer survivors. Acta Oncol 2015; 54: 772-779. 
11. Aerts L, Enzlin P, Verhaeghe J, et al. Sexual and psychological functioning in women after pelvic surgery for gynecological cancer. Eur J Gynaec Oncol 2009; 30: 652-656.

12. Wenzel LB, Donnelly JP, Fowler JM, et al. Resilience, reflection, and residual stress in ovarian cancer survivorship: a gynecologic oncology group study. Psychooncology 2002; 11: 142-153.

13. Andersen BL, Hacker NF. Psychosexual adjustment after vulvar surgery. Obstet Gynecol 1983; 62: 457-462.

14. Reis N, Beji NK, Coskun A. Quality of life and sexual functioning in gynecological cancer patients: results from quantitative and qualitative data. Eur J Oncol Nurs 2010; 14: 137-146.

15. Boggett A, Graham L, van Wersch A. Sexuality in Women Recovering from Gynecological Cancer. Int J Gynaecol Obstet 2015; 3: 1-6.

16. Grumann M, Robertson R, Hacker NF, Sommer G. Sexual functioning in patients following radical hysterectomy for stage IB cancer of the cervix. Int J Gynecol Cancer 2001; 11: 372-380.

17. Jongpipan J, Charoenkwan K. Sexual function after radical hysterectomy for early-stage cervical cancer. J Sex Med 2007; 4: 1659-1665.

18. Carter J, Huang H, Chase DM, et al. Sexual function of patients with endometrial cancer enrolled in the Gynecologic Oncology Group LAP2 Study. In J Gynecol Cancer 2012; 22: 1624-1633.

19. Juraskova I, Butow P, Bonner C, et al. Sexual adjustment following early stage cervical and endometrial cancer: prospective controlled multi-center study. Psychooncology 2013; 22: 153-159.

20. Rowlands IJ, Lee C, Beesley VL, Webb PM; Australian National Endometrial Cancer Study Group. Predictors of sexual well-being after endometrial cancer: results of a national self-report survey. Support Care Cancer 2014; 22: 2715-2723.

21. Pinar G, Kaplan D, Akalin Ayse, et al. Evaluation of sexual dysfunction and affecting factors in Turkish women with gynecological cancer. Sex Disabil 2015. DOI: 10.1007/s11195-015-9411-y.

22. Levin AO, Carpenter KM, Fowler JM, et al. Sexual morbidity associated with poorer psychological adjustment among gynecological cancer survivors. Int J Gynecol Cancer 2010; 20: 461-470.

23. Bourgeois-Law G, Lotocki R. Sexuality and gynecological cancer: A needs assessment. Can J Hum Sex Winter 1999; 8: 231-240.

24. Juraskova I, Butow P, Robertson R, et al. Post-treatment sexual adjustment following cervical and endometrial cancer: A qualitative insight. Psychooncology 2003; 12: 267-279.

25. Lindau ST, Gavrilova N, Anderson D. Sexual morbidity in very long term survivors of vaginal and cervical cancer:A comparison to national norms. Gynecol Oncol 2007; 106: 413-418.

26. Bukovic D, Silovski H, Silovski T, et al. Sexual functioning and body image of patients treated for ovarian cancer. Sex Disabil 2008; 26: 63-73.

27. Hawighorst-Knapstein S, Fusshoeller C, Franz C, et al. The impact of treatment for genital cancer on quality of life and body image - results of a prospective longitudinal 10-year study. Gynecol Oncol 2004; 94: 398-403.

28. Cleary V, Hegarty J. Understanding sexuality in women with gynecological cancer. Eur J Oncool Nurs 2011; 15: 38-45.

29. Green MS, Naumann RW, Elliot M, et al. Sexual dysfunction following vulvectomy. Gynecol Oncol 2000; 77: 73-77.

30. Sacerdoti RC, Lagana' L, Koopman C. Altered sexuality and body image after gynecological cancer treatment: how can psychologists help? Prof Psychol Res Pr 2010; 41: 533-540.

31. Novackova $\mathrm{M}$, Halaska $\mathrm{MJ}$, Robova $\mathrm{H}$, et al. A prospective study in the evaluation of quality of life after vulvar cancer surgery. Int J Gynecol Cancer 2015; 25: 166-173.

32. Tabano $M$, Condosta $D$, Coons $M$. Symptoms affecting quality of life in women with gynecologic cancer. Semin Oncol Nurs 2002; 18: 223-230.

33. Frumovitz $M$, Sun CC, Schover LR, et al. Quality of life and sexual functioning in cervical cancer survivors. J Clin Oncol 2005; 23: 7428-7436.

34. Zabora J, Brintzenhofe-Szoc K, Curbow B, et al. The prevalence of psychological distress by cancer site. Psychooncology 2001; 10: 19-28.

35. Gilbert E, Ussher JM, Perz J. Sexuality after gynecological cancer: A review of the material, intrapsychic, and discursive aspects of treatment on women's sexual-wellbeing. Maturitas 2011; 70: 42-57.

36. Ploos van Amstel FK, van Ham MA, Peters EJ, et al. Self-reported distress in patients with ovarian cancer: is it related to disease status? Int J Gynecol Cancer 2015; 25: 229-235.

37. Shand LK, Brooker JE, Burney S, et al. Symptoms of posttraumatic stress in Australian women with ovarian cancer. Psychooncology 2015; 24: 190-196.

38. Tang GX, Yan PP, Yan CL, et al. Determinants of suicidal ideation in gynecological cancer patients. Psychooncology 2016; 25: 97-103.
39. Butler L, Banfreld V, Sveinson T. Conceptualizing sexual health in cancer care/commentaries/authors' response. Western J Nurs Res 1998; 6: 683 705.

40. Lowdermilk D, Germino BB. Helping women and their families cope with the impact of gynecologic cancer. J Obstet Gynecol Neonatal Nurs 2000; 29: 653-660.

41. Drabe N, Wittmann L, Zwahlen D, et al. Changes in close relationships between cancer patients and their partners. Psychooncology 2013; 22: 13441352.

42. Hawkins Y, Ussher J, Gilbert E, et al. Changes in sexuality and intimacy after the diagnosis and treatment of cancer: the experience of partners in a sexual relationship with a person with cancer. Cancer Nurs 2009; 32: 271-280.

43. Gilbert E, Ussher JM, Perz J. Renegotiating sexuality and intimacy in the context of cancer: the experiences of carers. Arch Sex Behav 2010; 39: 9981009.

44. Quinn MA. Sexual function after treatment of gynecological cancer. Sexologies 2007; 16: 286-291.

45. Woźniak K, Iżycki D. Cancer: a family at risk. Prz Menopauzalny 2014; 13 253-261.

46. Ferrell B, Ervin K, Smith S, et al. Family perspectives of ovarian cancer. Cancer Pract 2002; 10: 269-276.

47. Ussher JM, Perz J. Gender differences in self-silencing and psychological distress in informal cancer carers. Psychol Women Q 2010; 34: 228-242.

48. Sjövall K, Attner B, Lithman T, et al. Influence on the health of the partne affected by tumor disease in the wife or husband based on a populationbased register study of cancer in Sweden. J Clin Oncol 2009; 27: 47814786.

49. Mortimer JS, Sephton SE, Kimerling R, et al. Chronic stress, depression and immunity in spouses of metastatic breast cancer patients. Clin Psychologist 2005; 9: 59-63.

50. Rohleder N, Marin TJ, Ma R, Miller GE. Biologic cost of caring for a cancer patient: dysregulation of pro- and anti-inflammatory signaling pathways. J Clin Oncol 2009; 27: 2909-2915.

51. Schulz R, Beach SR. Caregiving as a risk factor for mortality: the Caregiver Health Effects Study. JAMA 1999; 282: 2215-2219.

52. Stafford L, Judd F. Partners of long-term gynecologic cancer survivors: psychiatric morbidity, psychosexual outcomes and supportive care needs. Gynecol Oncol 2010; 118: 268-273.

53. Butow PN, Price MA, Bell ML, et al. Caring for women with ovarian cancer in the last year of life: A longitudinal study of caregiver quality of life, distress and unmet needs. Gynecol Oncol 2014; 132: 690-697.

54. Ratner ES, Foran KA, Schwartz PE, Minkin MJ. Sexuality and intimacy after gynecological cancer. Maturitas 2010; 66: 23-26

55. Vermeer WM, Bakker RM, Kenter GG, et al. Cervical cancer survivors' and partners' experiences with sexual dysfunction and psychosexual support. Support Care Cancer 2016; 24: 1679-1687.

56. Lalos A, Jacobsson L, Lalos O, Stendahl U. Experiences of the male partner in cervical and endometrial cancer: a prospective interview study. J Psychosom Obstet Gynaecol 1995; 16: 153-165.

57. Andersen BL, Woods XA, Copeland LJ. Sexual self-schema and sexual morbidity among gynecologic cancer survivors. J Consult Clin Psychol 1997; 65: 221-229.

58. Maughan K, Heyman B, Matthews M. In the shadow of risk. How men cope with a partner's gynecological cancer. Int J Nurs Stud 2002; 39: 27-34.

59. Carr SV. Psychosexual health in gynecological cancer. Int J Gynaecol Obstet 2015; 131 Suppl 2: 159-163.

60. Vermeer WM, Bakker RM, Kenter GG, et al. Sexual issues among cervical cancer survivors: how can we help women seek help? Psychooncology 2015; 24: 458-464.

61. Vermeer WM, Bakker RM, Stiggelbout AM, et al. Psychosexual support for gynecological cancer survivors: professionals' current practices and need for assistance. Support Care Cancer 2015; 23: 831-839.

62. Barbera L, Fitch M, Adams L, et al. Improving care for women after gynecological cancer: the development of a sexuality clinic. Menopause 2011; 18 : 1327-1333.

63. Wittmann D, Carolan M, Given B, et al. What couples say about their recovery of sexual intimacy after prostatectomy: toward the development of a conceptual model of couples' sexual recovery after surgery for prostate cancer. J Sex Med 2015; 12: 494-504.

64. Amoyal NR, Nisotel L, Dizon DS. Sexual Recovery After Cancer. Curr Sex Health Rep 2015; 7: 63-69. 